\title{
“A CAVALO DADO NÃO SE OLHAM OS DENTES"
}

\author{
Andreas Wacke \\ Professor Titular de Direito Romano, Civil e Processo Civil, e \\ Diretor do Instituto de Direito Romano da \\ Universidade de Köln, Alemanha.
}

\begin{abstract}
Resumo:
O dito alegórico sobre o cavalo dado difere, por seu caráter popular, dos brocardos jurídicos acadêmicos em grande parte inventados ou compilados durante a Idade Média. Para os camponeses, familiarizados com o mercado de animais, o provérbio alude à responsabilidade moderada dos doadores por vícios redibitórios, em contraste com as normas aplicáveis ao contrato de compra e venda. Devido à sua objetividade, a tradição oral pode ser considerada pertinente à esfera da "jurişprudência popular"; presta-se bem para a caracterização da atividade julgadora dos juízes leigos medievais (jurados): “os fazendeiros tendem a julgar por meio de ditados populares". Aquele adágio, que em sua versão latina remonta a São Jerônimo, não existiu com a mesma fraseologia no Direito Romano do Corpus Iuris Civilis. Mas a situação privilegiada do doador altruísta, sua isenção de responsabilidade por defeitos do objeto doado, a não ser em caso de dolo, pode já ser encontrada, em sua essência, no antigo Direito clássico. A idéia básica de que a generosidade de uma pessoa não pode resultar em prejuízo para essa mesma pessoa (Utilitätsprinzip), ainda hoje é convincente. Por essa razão, esse principio legal e ético, que contém ao mesmo tempo um preceito de conduta para o donatário, é difundido de forma tão-generalizada que quase se poderia falar de um princípio legal universal.
\end{abstract}

'Institut für römisches Recht der Universität zu Köln, D-50923 Köln, Alcmanha, c-mail: Andreas.Wacke@uni.kocln.dc. Agradcço de coração ao Prof. Dr. Dárcio Roberto Martins Rodrigucs, da Universidade de São Paulo, pcla tradução para o portuguĉs. Como bolsista da Hcinrich Hertz-Stiftung o Prof. Rodrigucs permaneccu no total um ano como pesquisador no mcu instituto $\mathrm{cm}$ Köln, $\mathrm{cm} 1995 \mathrm{c}$ 1998. Já há anos venho fazendo da análise científica dos princípios gerais do Direito cxpressos nos brocardos jurídicos como minha tarefa de pesquisa, tanto nos scminários por mim conduzidos na universidade quanto $\mathrm{cm}$ obras publicadas. Algum material a csse respeito se encontra publicado na colctânca: Andreas Wacke, Estudios de Derecho Romano y moderno en cuatro idiomas (Madrid, Universidad Complutense, 1996) p. 579. Como pequena amostra, posso aqui publicar, graças à colaboração do Profcssor Rodrigues, algumas considerações sobre um dos mais conhecidos brocardos jurídicos. 


\begin{abstract}
:
The allegoric saying about the gift horse differs from the scholarly legal maxims - to a large extent coined or compiled in the Middle Ages - by its popular character. For farmers familiar with the cattle trade the proverb points to the moderate liability of donors for defects in the object of donation, in contrast to the rules applicable to the contract of sale. Due to its plainness, oral tradition can be regarded as pertinent to the sphere of "popular jurisprudence"; it is suitable for the characterization of the judging activity of medieval layman judges (jurors): "farmers tend to judge by means of proverbs" The adage, that in its Latin version traces back to Jerome, did not exist in that same wording in the Roman Law of the Corpus Iuris Civilis. But the privileged situation of the unselfish donor, its exemption from liability for defects of the object of donation, except in case of malice (dolus), can be already found, in its essence, in ancient classical law. The basic idea that a person's generosity may not result in damage for that same person (Utilitätsprinzip), is still quite convincing today. For that reason, this legal and ethical principle, which at the same time contains a direction for the conduct of the donee, is so generally widespread that one could almost speak of a universal legal principle.
\end{abstract}

Unitermos: brocardo, doação, vícios redibitórios.

1. A expressão se encontra entre os brocardos jurídicos mais citados ${ }^{1} \mathrm{e}$ se espalhou por todos os idiomas; em francês: $A$ cheval donné on ne regarde pas à la dent (ou: on ne regarde point à la bouche); em espanhol: $A$ caballo regalado no le mires el diente; em italiano: A cavallo donato non si guarda in bocca; em inglês: Don't look a gift horse in the mouth. A presumivel origem comum acha-se, em latim, em São Jerônimo (347-420 d. C.): Noli equi dentes inspicere donati, ${ }^{2}$ ou Donato nonsunt ora inspicierida caballo. A versão alemã "Einem geschenkten Gaul schaut man nicht ins Maul" apresenta como única vantagem sobre as demais a rima, a qual chama mais a atenção. Por outro lado, "Maul" (boca) é um termo menos preciso do que "Zahn" (dens, dente etc.).

Um comprador há que se precaver contra as manobras fraudulentas do vendedor (caveat emptor; curiosus esse debet) e, no comércio de animais, sobretudo

1. A. Foth, Gelehrtes römisch-kanonisches Recht in deutschen Rechtssprichwörtern (Tübingen 1971) 174f.; R. Sclımidt-Wicgand, Deutsche Rechtsregeln und Rechtssprichwörter (1996) s.v. "Gaul". "schenken", com ricas remissões. 
contra os proverbiais métodos dolosos dos mercadores de cavalos (Roßtäuschermethoden), ${ }^{3}$ por meio da chamada Maulprobe (exame bucal): pelo estado da arcada dentária (mas também pelos olhos e cascos) um conhecedor de cavalos é capaz de avaliar-lhe a idade com relativa precisão. Daí os ditados: "Pelos dentes se conhece o cavalo" — "Apalpar os dentes de alguém" (modo de dizer emprestado do comércio de cavalos, no sentido de: examiná-lo intensivamente, sondá-lo) — "Cachorros velhos têm dentes gastos" "Roído pelo dente do tempo" (com relação a coisas muito desgastadas) tornou-se proverbial a partir do "tooth of time", de Shakespeare (Measure for Measure, $V, i, 12)$.

Os franceses chamam o mercador de cavalos de maquignon, presumivelmente do holandês makelen, mercadejar (daí também, em alemão, 'Makler' corretor). Maquignonner = faire paraître un cheval meilleur qu'il est, pour mieux le vendre; maquignonnage = moyens qui'il emploie pour dissimuler les défauts d'un cheval.

2. Migne 26, 469. São Jcrônimo já o chama de vulyare proverbitum, no prefäcio aos scus comentários à Epistola aos Efćsios. Cf. Lutz Röhrich, Lexikon der sprichwörtlichen Redensarten (2. ed. 1994) s. v. 'Gaul', com bibl.; Simpson, The Concise Oxford Dictionary of Proverbs s.v. 'Gift', com paralclismos ingleses. Em C. S. Köhler, Das Tierleben im Sprichwort der Griechen und Römer (1881, rcimpr. 1967)s. v. 'Pferd' não sc cncontra. Erasmus, Adagia 4,5,24 o inclui cntrc os hodic iactata, cf. S. SINGER, Sprichnörter des Mittelalters I (1944) p. 134 com outras versõcs latinas do sćc. XI.

Calvo, un comandante mercenário cspanhol a serviço da França c apaixonado admirador de cavalos, destacou-se sob Luis XIV na heróica defesa da cidade de Maastricht, sitiada por Guilherme III de Orange. Propondo-lhe Luis XIV trocar de cavalo com cle, Calvo recusou, comentando que antes daria ao rci a sua csposa, se cle a exigissc. "É que a tua csposa já não tem mais dentes", redargüiu o rei. Calvo replicou com o dictum accrca do cavalo dado; cf. F. F. W. Wander, Deutsches Sprichwörter-Lexikon (1867, Neudruck 1987) S.v. 'Gaul' c/ vasta documcntaçào. O próprio Luís XVI teve todos os dentes cxtraídos, a consclho de scu médico; por causa de tal charlatanice teve cle que suportar sofrimentos atrozes pelo resto de sua vida; narrado com clareza por H.G. Zander, Zanderfilets: Kabinettstïcke aus der Rumpelkammer der Geschichte (1992) 9 ss.

3. 'Täuschen' (enganar) c 'tauschen' (permutar) têm a mesma raiz ctimológica (muitas vezes cmpregada $\mathrm{cm}$ trocadilhos): $\mathrm{dc}$ tituschen = falar com falsidade, impingir alguma coisa (fraudulcnta) $\mathrm{cm}$ um negócio. O mercador de cavalos se chamava, antes de 1300, rostiuschaere, cf. Kluge/Mitzka, Etymologisches Wörterbuch s.v. 'Tausch', 'Roßtäuscher'. Os métodos usuais dos mercadores no comćrcio de cavalos sào caricaturados cm uma ancdota da colctânca 'Wenclunmutu' (scgunda metade do séc. XVI): Em idade avançada, um mercador de cavalos cntra para um mostciro na condição de irmão lcigo, a fim de levar dali por diantc uma vida mais regrada. Por incumbência do abadc, cle ć, certo dia, cncarregado de vender no mercado um cavalo que já não cra novo. Tendo, no cntanto, para salvação de sua alma, renunciado à mentira $\mathrm{c}$ à trapaça que trazer de volta o cavalo, ao fim da tarde, $\mathrm{sem}$ que o tivesse conseguido vender. O abade o admocstou severamente, por ter cle se portado de modo tão-tolo e simplório, revelando de imediato todos os defcitos do cavalo. Moral da história: Quando um mercador de cavalos se torna devoto c entra para um mostciro, não consegue mais vender cavalo algum. 
Os métodos mais modernos para o exame de animais afastaram os proverbiais métodos dos mercadores de cavalos (por exemplo pequenas misturas de arsênico na ração) da nossa realidade jurídica. Inseminação artificial, assistência veterinária no parto, marcas a fogo e sobretudo (ao menos oficiosamente) árvores genealógicas (pedigrees) de cavalos-de-raça atestam a idade e a origem de um cavalo com maior segurança, do que o tradicional exame bucal. Para valores de mercado, até meio milhão de marcos alemães, tais medidas de proteção ao comprador são também obrigatórias. Por isso, o nosso brocardo tem hoje quase que apenas um significado alegórico.

O proprietário de um cavalo velho poupa-se das despesas para o continuar alimentando se um terceiro o aceitar como presente. Para certificar-se, no entanto, de que o adquirente não venderá logo o cavalo como animal de abate, deve o proprietário procurar um interessado que lhe ofereça por ele ao menos o seu preço de abate.

2. "Não se devem contar os dentes de um cavalo dado" Isso significa que o donatário não deve fazer caso de pequenos defeitos, ele não deve pôr-se a criticar de modo mesquinho o objeto de uma doação; afinal ele nada precisou despender para adquiri-lo. "Não se deve reprochar um presente recebido" (Freidank, séc. XIII). Quem recebe alguma coisa como presente não pode ser muito exigente: Celui à qui on donne, ne choisit pas. "Sendo dado, já basta!"4 Até o mínimo presente é digno de agradecimentos. Quem não agradece um presente pequeno não merece um grande. Chose donnée doit être louée. Atente-se menos para o valor do presente do que para o bom coração do doador; em italiano: Non si guarda il dono, ma il bon cuore del donatore; em espanhol: No es rico el don por el valor, sino por el amor. Um presente fecha a boca do doador (que não precisa avisar acerca de pequenos defeitos) e abre a do donatário, dizem também os italianos: Il dono chiude la bocca a chi lo fa, ed apre a chi lo riceve. Abreviadamente: "Quem dá, silencie, fale quem recebe." "Ovos dados são sempre frescos": para o presenteado eles precisam sê-lo. "Recebida de presente, uma maçã azeda é doce", diz um provérbio da Letônia. Um convidado bem-educado também não-critica a comida que lhe é servida. Quanto mais ele parecer estar comendo com

4. Ditado succo; cm Wander, 'Schenken' n. 8. O presenteado pode, no cntanto, recusar o prescnte; não existe contradição ao principio beneficia non obtruduntur.

5. Ditado russo; cm Wander n.8. 
apetite, maior homenagem ele presta ao anfitrião. ${ }^{6}$ De gratuito munere non estjudicandum. ${ }^{7}$ Aceitam-se os presentes na condição em que foram dados; Donumquodcumque probandum. ${ }^{8}$ Presentes são sempre a mais agradável das aquisições: Il n'est si bel acquêt que le don. Il signor Donato è sempre ben arrivato. De acordo com um adágio espanhol, aquilo que é dado é até duas vezes bem-vindo: Lo dado es dos veces grato. Também, por pilhéria: "Dado nunca é ruim, desde que não seja paulada": Lo dado nunca es malo, como no sean palos (palos aqui = bordoadas).

3. Por isso, o doador só está obrigado a indenizar por danos no caso de vícios da coisa ocultados dolosamente, $\$ 524$ do BGB (Código Civil alemão). O mesmo vale para a evicção, $\$ 523$ BGB. Por benfeitorias realizadas por um donatário de boafé sobre uma coisa alheia doada, o doador de boa-fé não responde após a evicção (D. $39,5,18,3=6,1,48)$. A razão disso é: Nemini sua liberalitas damnosa esse debet." A ninguém deve uma liberalidade sua trazer prejuízo, fazendo-llhe surgir daí outros deveres. Por vícios redibitórios ou evicção limita-se a obrigação do doador (semelhantemente a um devedor por enriquecimento sem causa) a um simples dever de entrega. ${ }^{10} " 1 \mathrm{~A}$ atenuação da responsabilidade daquele que não está agindo em interesse próprio deve, no sentido da teoria dos deveres de Pufendorf, encorajar todas as pessoas a ajudar os outros, deve estimulá-las a agir com caridade e destarte promover o bem-estar do próximo. ${ }^{12}$ A responsabilidade atenuada de quem não-age em proveito próprio nós chamamos de Utilitätsprinzip (de utilitas, utilidade, proveito). ${ }^{13}$ Ela se aplica também

6. Um fenômeno humano gencralizado, muitas vezes obscrvado por Marcel Mauss, "Essai sur le don", L'année Sociologique n.s. 1, 1923-24 (1925) 30-186; citado conforme a tradução alcmã de Eva Moldenhaucr: Die Gabe, Form und Funktion in archaischen Gesellschaften (Frankfurt/M. 1968), rcimpresso cm M. Mauss, Soziologie und Anthropologie II (München/Wien 1975) pp. 9-144, aqui p. 77, muitas vezes obscrvado por Marccl Mauss.

7. São Jcrônimo (cf. sutpra, nt. Vh 2); citado (como o scguintc) conformc A. Loyscl Institutes coûtumiers's (1846, réimpression Genc̀ve 197I) n. 655.

8. Wander; 'Geschenk'n. 42.

9. Licbs, Lateinische Rechtsregeln und Rechtssprichwörter (6. cd. 1997) n. N-28.

10. Abgabesc/ruld, i.c., o dever de apenas entregar aquilo que se tem, sem nenhuma responsabilidade mais rigorosa alćm disso.

II. Cf. O. von Gicrke, Deutsches Privatrecht III. Schuldrecht (1917) 424f., 426.

12. Essa ratio do chamado Utilitätsprinzip é negligenciada por Grundınann, Archiv für dic civilistische Praxis 198 (1998) 461 ss. cm scu apclo por um agravamento da responsabilidade do devedor.

13. R. Zimmormann, The Law of Obligations (1990) 198 ss. passim (v. indice). 
aos danos resultantes de vícios ou defeitos da coisa (violação do interesse de integridade ${ }^{14}$ do donatário). ${ }^{15}$ Ela também vale (como o nosso brocardo) com relação a um comodante ( $\$ 599$ ss. do BGB). Por força do $\$ 522$ do BGB não se é obrigado a pagar juros de mora por uma promessa de doação.

Uma qualidade mediana, característica de uma mercadoria de valor médio, também não se pode sempre exigir em uma promessa de doação (com exceção do $\$ 243$ inciso 2 do BGB, $\$ 360$ do HGB [Código Comercial Alemão])." Esse padrão é válido para obrigações genéricas onerosas. Quem recebe algo sem ônus não pode, em regra, rejeitar uma coisa de qualidade abaixo da média como se fora inadequada para o cumprimento da prestação, desde que não esteja defeituosa. ${ }^{17}$ Se estiver estipulado que o doador deverá primeiro adquirir o objeto a ser doado, então de acordo com o $\$$ 523 ss. (cf. inciso $2^{\text {a }}$ ) do BGB ele só responderá pelos vícios ou pela evicção dos quais tiver conhecimento por ocasião da posterior aquisição ou que permanecerem desconhecidos por negligência dele. Quem transfere gratuitamente a terceiros uma herança, após a delação, esses também têm sua responsabilidade atenuada, conforme o $\S 2.385$, inciso $2^{\text { }}$ (do último preceito) do BGB, ou seja, (excetuando-se o $\$ 2.375$ ) somente pela sua existência atual e não por diminuições não-onerosas ocorridas anteriormente; isso também se aplica analogamente para o caso de doação de todo o patrimônio de um terceiro.

Mercadoria não-vendável (por exemplo, alimentos que já não estejam bem frescos) sempre se pode ainda, por conseguinte, doar, e praticar com isso uma boa

14. Integritätsinteresse: intcresse que o individuo tem na manutenção da integridade de sua situação patrimonial. Trata-sc de terminus technicus da linguagcm juridica $\mathrm{cm}$ alcmão. No caso ora $\mathrm{cm}$ cxamc, cssc interesse scria violado sc, por cxcmplo, o cavalo dado não somente cstivessc docntc, mas ainda por cima transmitisse sua molćstia aos demais cqüinos do donatário, dcixando-o cm situação patrimonial pior do que aquela na qual se cncontraria se não tivessc reccbido a doação. (N. do T.).

15. Cf. os cxcmplos dé responsabilidade por dolo, infira n. 4. Diversamentc agora Grundmann, AcP 198 (1998) $46 \mathrm{I} \mathrm{ss.}$

16. E. GRAF / M. Dictherr, Deutsche Rechtsspric/hwörter (2. Aufl. 1869, reimpr. 1975) S. 257 (zu n. 171, 172). No dircito romano, todo devedor de obrigação genćrica sem garantia cspecial ("optimuss") podia dar o pior exemplar (pessimuss) que ainda correspondesse ao gêncro: Javolen Dig. 17, I,52. Essa solução, correspondente à regra da ambigüidade (ambiguitas contra stipulatorem), foi posteriormente restrita; v. Kascr, Das römische Privatrecht / (2. cd. 197I) 495 ss. c nt. 16.

17. Em conformidade com isso, o herdciro para fim do pagamento de um legado promessa de doação (cspecialmentc a partir de bens da herança) não deve cntregar a coisa da jior qualidade (pois isso lhe traria vantagem): Ulp. Dig. 30, 37pr. (ne optimus vel pessimus). De um modo geral, Justiniano declarou que o status mediocris (a mediocritas) cra aplicávcl tambćm para promessas de doação, C. 8,53[54],35, I-2 (530); Cf. Windscheid, Lehrbuch der Pandekten (8. cd. 1908) Il $\$ 366 \mathrm{c}$ nt. 10, mas tambcm $\$ 255 \mathrm{nt} .16$. 
ação, (em italiano: $\dot{E}$ buono donare la cosa che non si può vendere; em espanhol: Bueno es dar lo que no se puede vender), quiçá em benefício de um asilo de indigentes. Roupas de que não mais se precisa são doadas para campanhas de caridade (uma oferta de doação ad incertam personam ou derrelição). Que a mercadoria doada cheira mal, como transmitiu São Jerônimo em forma de provérbio, ${ }^{18}$ é de todo modo exagerado. Com peixe que já cheira mal um peixeiro dificilmente poderia atrair freguesia para si, ainda que distribuísse de graça. Em vez de esperar até que o rato as devore, alimentese antes o gato com as provisões de que não se necessita (espanhol: Lo que has de dar al rato, dáselo al gato). Para evitar que o preço decaia, mercadorias perecíveis são muitas vezes convertidas em alimento para gado (entre outros exemplos, cargas de containers cheios de pão velho) ou lastimavelmente até destruídas. ${ }^{19}$

A inaplicabilidade do direito edilício dos vícios ocultos ( $\$ 459$ ss. do BGB) para a doação origina-se no Direito Romano clássico (Dig. 21,1,62). Era - e é - excluída principalmente a redibição; um abatimento já se exclui de imediato, pois nenhum preço é devido. No Direito alemão da Idade Média não se encontra nenhuma regra especial nesse tocante com relação à doação. ${ }^{20}$ A responsabilidade atenuada do doador, nós recebemos do Direito Romano; a forma proverbial alegórica, adequada para uso generalizado como regra de conduta, devemos à transmissão de São Jerônimo.

4. Por ação premeditada (dolus) o doador deve, no entanto, responder, por exemplo, se ele deliberadamente doa um escravo ladrão e este furta alguma coisa ao donatário (Dig. 30,110); ou uma bicicleta comprometida por um vício oculto, com a qual o donatário sofre um acidente.

É ainda condenável o funesto presente de grego, conhecido da mitologia grega, o enorme cavalo de madeira com guerreiros escondidos em seu interior, contra o qual o perspicaz sacerdote Laocoon alertou em vão os troianos sitiados: um presente suspeito, que promete vantagens, mas oculta em si maleficios; dele deve-se ter receio,

18. Mer:x ultronea putet; rcferido por Karl Bayer, Nota bene: Das lateinische Zitatenlexikon (München, s/d.) n. 1.180 .

19. Como cxcmplo, duas notícias cxtraidas dos jornais: 1. Sucata de computadores velhos presta-sc bem para o restauro de rodovias, conforme cxpcriĉncias realizadas nos EUA. Podcmos cntão falar litcralmente de "Daten-Autobahnen" [Nota Do Tradutor: Ao pé da letra: "Daten-Autobahn" significa "rodovia de dados"; cssa expressão ć comumente cmpregada cm alcmào para designar o tráfego de dados na informática. Com tal alusão o autor fcz aqui um fino trocadilho cspirituoso] 2. A ministra da Educação alemã recentemente instou as cmpresas a não sucatcar computadorcs com defcito, mas antes doá-los a cscolas, para que os alunos possam adcstrar-sc na utilizaçào de computadorcs.

20. Foth op. cit. (cf. nt. $\backslash \mathrm{h} I$ ). 
segundo Virgílio (Aeneis 2,49). Sêneca o chamava de Danaum fatale munus (Agamemnon 624). Oferendas de inimigos não são presente nem lucro, dizia Sófocles (Ajax 665). Não raro se ocultam atrás delas ardis de guerra ou desejos de vingança. Hostium munera non sunt munera. Presentes de inimigos são perigosos. Don d'enemi c'est malencontre. Presentes de inimigo encerram ciladas, ${ }^{21}$ são como falsos brilhantes. Por isso, seja atento, veja bem quem lhe quer presentear algo (em italiano: Da chi ti dona, guardati). Os presentes de um velhaco são pérfidos (I doni di un perfido sono perfidi doni). Os presentes de um malvado se assemelham ao doador (Il dono del cattivo è simile al suo padrone). De mão ruim não vem nenhum presente bom (em espanhol: De mala mano, munca buen dado). O que um inimigo te dá de presente, não é com boaintenção. Os desconfiados germanos não aceitavam nenhum presente de desconhecido, se as circunstâncias o permitissem. ${ }^{22} \mathrm{O}$ invencível Hércules pereceu com dores atrozes por meio da túnica corrosiva embebida no sangue do falecido centauro Nessos, morto por ele, a qual lhe presenteou Dejanira (esposa de Hércules), supondo tratar-se de um filtro de amor, quando este se sentiu atraído por ĺole: uma vingança póstuma do centauro mediante o emprego de um recurso ardiloso. A evolução semântica da palavra alemã 'Gift' ${ }^{23}$ (veneno) concentroul-se no sentido de prejudicial à saúde, ou mesmo mortífero. No Sachsenspiegel (célebre livro jurídico escrito D.C. 1220-1235 pelo cavaleiro saxônio Eike von Repgow) 'gift' significava, como em inglês, o mesmo que 'presente'

5. "O cavalo dado": com este nome intitulou com propriedade a atriz Hildegard Knef o seu livro de memórias (Der geschenkter Gaul, Wien, 1970). O ditado vale para todos nós. Pois a nossa vida é um presente de Deus. Aceitemô-la com gratidão, tal como ela é (telle quelle; ainda que algumas vezes ela derrube o cavaleiro da sela). Da imperfeição dela não nos devemos queixar a Deus.

São Paulo, janeiro de 2001.

21. Cf. A. Arthaber, Dizionario comparato di proverbi etc. in sette lingue (ristampa Milano 1986) n. 445.

22. L. Hellmuth, Gastfieundschaft und Gastrecht bei den Germanen, Sitzungsberichte d. österreichischen Akademic der Wisscnschaften, Phil.-hist. Klassc 440 (Wien 1984) 273.

23. O significado original conscrvou-sc cm 'Mitgift' (dotc). A ligação com 'geben' (dar) demonstrasc no grcco-latino dosis. O francĉs/inglês poison deriva do latim potio (poção). Cf.. Klugc/Mitzka (supra nt. (h 3) s. v. 